\title{
(a) Betamethasone induces potent OPEN ACCESS immunosuppression and reduces HIV infection in
a PBMC in vitro model
}

\author{
Ross Cromarty (D) ,' Alexander Sigal, ${ }^{2,3}$ Lenine Julie Liebenberg, 1,4 \\ Lyle Robert Mckinnon, 1,5 Salim Safurdeen Abdool Karim, 1,6 \\ Jo-Ann Shelly Passmore, 1,7 Derseree Archary ${ }^{1,4}$
}

Additional material is published online only. To view, please visit the journal online (http://dx.doi.org/10. 1136/jim-2020-001424).

For numbered affiliations see end of article.

Correspondence to Dr Derseree Archary, Mucosal Immunology Laboratory, CAPRISA, Durban 4013, KwaZuluNatal, South Africa; desh.archary@caprisa.org

Accepted 25 August 2020 Published Online First 1 October 2020

\section{Check for updates}

(C) American Federation for Medical Research 2021. Re-use permitted under CC BY-NC. No commercial re-use. Published by BMJ.

To cite: Cromarty $\mathrm{R}$, Sigal A, Liebenberg LJ, et al. J Investig Med 2021;69:28-40.

\section{ABSTRACT \\ Genital inflammation is an established risk}

factor for increased HIV acquisition risk. Certain HIV-exposed seronegative populations, who are naturally resistant to HIV infection, have an immune quiescent phenotype defined by reduced immune activation and inflammatory cytokines at the genital tract. Therefore, the aim of this study was to create an immune quiescent environment using immunomodulatory drugs to mitigate HIV infection. Using an in vitro peripheral blood mononuclear cell (PBMC) model, we found that inflammation was induced using phytohemagglutinin and Tolllike receptor (TLR) agonists Pam3CSK4 (TLR1/2), lipopolysaccharide (LPS) (TLR4) and R848 (TLR7/8). After treatment with anti-inflammatory drugs, ibuprofen (IBF) and betamethasone (BMS), PBMCs were exposed to HIV NL4-3 AD8. Multiplexed ELISA was used to measure 28 cytokines to assess inflammation. Flow cytometry was used to measure immune activation (CD38, HLA-DR and CCR5) and HIV infection (p24 production) of CD4+ T cells. BMS potently suppressed inflammation (soluble cytokines, $\mathrm{p}<0.05$ ) and immune activation (CD4+ T cells, $\mathrm{p}<0.05)$. BMS significantly reduced HIV infection of CD4+ T cells only in the LPS $(0.98 \%)$ and unstimulated $(1.7 \%)$ conditions $(p<0.02)$. In contrast, IBF had minimal anti-inflammatory and immunosuppressive but no anti-HIV effects. BMS demonstrated potent anti-inflammatory effects, regardless of stimulation condition. Despite uniform immunosuppression, BMS differentially affected HIV infection according to the stimulation conditions, highlighting the complex nature of these interactions. Together, these data underscore the importance of interrogating inflammatory signaling pathways to identify novel drug targets to mitigate HIV infection.

\section{INTRODUCTION}

HIV remains a public health challenge with an estimated 1.8 million new infections globally in 2017. ${ }^{1}$ South Africa is disproportionately affected by HIV, harboring 20\% of the world's HIV-infected population, and women in this region account for $60 \%$ of these infections. ${ }^{2}$

\section{Significance of this study}

What is already known about this subject?

- HIV is a global epidemic with no vaccine or cure. Due to various social, behavioural and biological factors, women remain particularly vulnerable to HIV.

- Genital inflammation significantly increases the risk of HIV acquisition in women.

- Genital inflammation has also been shown to significantly reduce the efficacy of topical pre-exposure prophylaxis.

What are the new findings?

- In this in vitro model, we used various Toll-like receptor (TLR) agonists to simulate inflammation, and two anti-inflammatory drugs (ibuprofen (IBF) and betamethasone (BMS)) were tested to understand their role in modifying HIV infection.

- IBF showed minimal immunosuppressive or anti-inflammatory effects, in contrast to other studies, and did not lower HIV infection of CD4+ T cells.

- Despite potent uniform immunosuppression, BMS differentially affected HIV infection of CD4+ T cells according to the TLR stimulation condition.

Despite high levels of protection in clinical trials testing antiretroviral drugs as pre-exposure prophylaxis (PrEP) in men who have sex with men, ${ }^{3-6}$ inconsistent levels of protection have been shown among heterosexual populations, particularly in African women. ${ }^{7-11}$ While adherence to PrEP likely undermines protection in women, ${ }^{12}$ biological factors such as genital inflammation ${ }^{13-16}$ are known to increase women's susceptibility to HIV, even in those using PrEP. ${ }^{17-20}$

Inflammation, a necessary natural response elicited by the body to control infection and limit tissue damage 2122 is initiated through the recognition of pathogen-associated molecular patterns (PAMPs) and damage-associated molecular patterns, respectively, by pathogen 


\section{Significance of this study}

How might these results change the focus of research or clinical practice?

- The results of this study suggest BMS may be used as a potential preventative strategy to limit HIV acquisition in women. The use of anti-inflammatories to reduce HIV transmission is not a new concept. However, this is the first study to show reduced HIV infection with an antiinflammatory drug, despite the limitations of the model. Furthermore, these results underscore the importance of interrogating signaling pathways in response to stimulation to determine novel drug targets to mitigate risk of HIV infection.

recognition receptors. These include Toll-like receptors (TLRs) that are expressed both inside and on the cell surface on many cell types, particularly innate immune cells. ${ }^{23-27}$ Some of the most potent PAMPs that exert significant immunological and inflammatory responses include bacterial lipopeptides recognized by TLR2 $2{ }^{28-30}$ lipopolysaccharide (LPS) recognized by TLR4, ${ }^{31-34}$ and single-stranded RNA recognized by TLR7/8. ${ }^{35-37}$ Although inflammation is necessary to mount a successful host defense against pathogens, it can lead to pathology if dysregulated and persistent.

Genital inflammation is associated with immune activation and recruitment of HIV target cells, in addition to disrupting the mucosal barrier. Immune activation and increased concentrations of cytokines in the genital tract $^{1438}$ and in blood ${ }^{39} 40$ have directly been associated with increased HIV acquisition risk. Inflammatory cytokines activate $\mathrm{CD} 4+\mathrm{T}$ cells, targets for $\mathrm{HIV}{ }^{41}$ which are preferentially and more easily infected than resting CD4+ $\mathrm{T}$ cells. ${ }^{42-44}$ Chemokines secreted by mucosal epithelial cells recruit innate immune cells, such as plasmacytoid dendritic cells, which in turn produce other chemokines to attract HIV target cells. ${ }^{45}$ Inflammation and cellular recruitment are important precursors for establishment of simian immunodeficiency virus (SIV) infection following vaginal challenge in Rhesus macaques. ${ }^{45}$ These findings were confirmed in sooty managabeys where protection against SIV infection was associated with lower levels of systemic and mucosal CD $4+$ CCR $5+$ T cells. ${ }^{46}$ In humans, increased chemokines in the genital tract conferred more than threefold increased risk of HIV acquisition. ${ }^{14}$ Similarly, increased mucosal concentrations of inflammatory cytokines compared with plasma were associated with increased HIV risk. ${ }^{47}$ Inflammation even in HIV-negative individuals resulted in recruitment of HIV target cells and epithelial barrier disruption. ${ }^{48-50}$ Nazli et al demonstrated that coculture of mucosal epithelial cells with infectious HIVstimulated inflammatory cytokines, which in turn compromised the epithelial barrier leading to increased mucosal barrier permeability. ${ }^{51-54}$ Some known causes of genital inflammation include vaginal microbial dysbiosis and sexually transmitted infections. ${ }^{175-61}$ However, while there are many potential causes of genital inflammation, eliminating these causes may not fully reverse their negative effects, further necessitating additional interventions. Therefore, understanding the complex associations between HIV and the biological factors that drive susceptibility is crucial.

Multiple studies have reported reduced immune activation in HIV-exposed seronegative (HESN) individuals, ${ }^{62-67}$ which was suggested to confer protection in these individuals against HIV acquisition. Safe, licensed, and easily obtainable drugs that modulate immunity to induce an immune quiescent phenotype to reduce HIV acquisition risk are a theoretically attractive option. Recently, antiinflammatory drugs like acetylsalicylic acid (ASA, commonly known as aspirin) and hydroxychloroquine (HCQ) were shown to reduce inflammation and immune activation of CD4+ Tand Th17 cells systemically and at the mucosa of low-risk uninfected women who were taking these oral drugs daily for 6 weeks. ${ }^{68}$ Furthermore, HCQ also reduced systemic inflammatory cytokines. ${ }^{68}$ Even though the work by Lajoie et al demonstrated proof of principle that nonsteroidal anti-inflammatory drugs (NSAIDs) can reduce the proportion of target CD4+ CCR $5+$ and Th17 cells in women, this study did not investigate the effects of these two anti-inflammatory drugs in preventing HIV infection. Similarly, in HIV-infected individuals, chloroquine (CQ) and HCQ significantly reduced HIV-associated immune activation. ${ }^{69-72}$ Additionally, in a small animal model, an HCQ implant, compared with a placebo, reduced recruitment of immune cells to the genital tract, improved mucosal epithelial integrity and reduced T-cell activation and inflammatory cytokines. ${ }^{73}$ Topical application of a glucocorticoid (GC) drug like betamethasone (BMS) ${ }^{74}$ or an NSAID like ibuprofen $(\mathrm{IBF})^{75}$ have also demonstrated efficacy for treating inflammatory skin conditions and genital inflammation, respectively. Furthermore, a natural product like glycerol monolaurate, which has anti-inflammatory properties, showed efficacy in reducing SIV infections in rhesus macaques. ${ }^{45} 76$ These data demonstrate the capacity of anti-inflammatory drugs to reduce immune activation and inflammation as additional modalities toward mitigating HIV risk.

The use of anti-inflammatory drugs to reduce genital inflammation and mucosal immune activation, to mitigate HIV acquisition risk in women, may be plausible in regions with high levels of genital inflammation and HIV burden. The use of such products requires thorough preclinical testing to assess the viability, utility and efficacy of such strategies. Using a peripheral blood mononuclear cell (PBMC)-based in vitro model for HIV infection, we tested the hypothesis that modulating TLR-induced inflammation with anti-inflammatory drugs, including IBF and BMS, reduced inflammatory responses, immune activation and HIV infection.

\section{MATERIALS AND METHODS}

\section{Isolation and culture of PBMCs with HIV}

For each experiment, PBMCs were isolated from fresh blood collected from four healthy HIV-negative donors by density gradient centrifugation. ${ }^{77}$ PBMCs were resuspended to $1 \times 10^{6}$ cells $/ \mathrm{mL}$ in C10 media and placed into 24-well cell culture plates. For all cell culture experiments, C10 media consisting of Roswell Park Memorial Institute medium (RPMI) 1640 with L-glutamine (Lonza, Basel, Switzerland) containing $10 \%$ fetal calf serum 
(FCS) (non-heat inactivated FCS; Highveld Biological (PTY) LTD, Johannesburg, South Africa), 2\% L-glutamine, $1 \%$ 4-(2-hydroxyethyl)-1-piperazineethanesulfo nic acid (HEPES), 1\% sodium pyruvate (NaPy), and 1\% non-essential ammino acids (NEAA) (all from Lonza) was used. Interleukin (IL)-2 (PeproTech, Rocky Hill, New Jersey, USA), added to C10 media prior to use, was used at a final concentration of $0.01 \mu \mathrm{g} / \mathrm{mL}$. Unstimulated PBMCs were used as the negative control and stimulation with phytohemagglutinin (PHA) (Sigma-Aldrich, St. Louis, Missouri, USA) was used as the positive control, at a final concentration of $10 \mu \mathrm{g} / \mathrm{mL}$. The CCR 5 -tropic HIV-1 NL4-3 AD8 ${ }^{78}$ was used at an multiplicity of infection (MOI) of 0.9 , as previously described. ${ }^{77}$

\section{TLR agonists and anti-inflammatory drugs}

TLR agonists LPS (TLR4), R848 (TLR7/8) and Pam3CSK4 (TLR1/2) (all from Invivogen, San Diego, California, USA) were used at a final concentration of $2 \mu \mathrm{g} / \mathrm{mL}$, as described previously. ${ }^{77}$ In addition to these TLR agonists, the following anti-inflammatory drugs were used in this study: IBF and BMS (both from Sigma-Aldrich). IBF was resuspended in sterile PBS, while BMS was initially resuspended in 100\% ethanol before diluting 1:5 with sterile PBS, and both drugs were used at a final concentration of $1 \mu \mathrm{g} / \mathrm{mL}$, which was the drug concentration previously optimized in anti-inflammatory drug titration experiments (data not shown).

\section{Treatment of PBMCs with TLRs, anti-inflammatory drugs and HIV}

PBMCs were treated with either IBF or BMS or left untreated (negative control) and incubated at $37^{\circ} \mathrm{C} \quad 5 \% \quad \mathrm{CO}_{2}$ for 2 hours. Following this incubation period, PBMCs were left either unstimulated (negative control) or stimulated with TLR agonists or PHA (positive control) then incubated for 48 hours at $37^{\circ} \mathrm{C} 5 \% \mathrm{CO}_{2}$. Following this incubation (for the day 3 time point, 48 hours poststimulation but prior to HIV exposure), both PBMCs and culture supernatants of each well were collected into sterile tubes for flow cytometry analysis and multiplex ELISA experiments, respectively. The tubes containing the remaining PBMCs (that were subsequently exposed to HIV-1 NL4-3 AD8, as described further) were centrifuged; supernatants were discarded; and media replacements were performed with fresh C10 media. PBMCs were then plated at $1 \times 10^{6}$ cells $/ \mathrm{mL}$ into 24 -well cell culture plates; no further stimulations were performed. Subsequently, $250 \mu \mathrm{L}$ of 1:20 diluted HIV-1 NL4-3 AD8 viral stocks (a gift from Dr Alex Sigal), corresponding to an MOI of 0.9 , was added to expose PBMCs to HIV for infection. PHA and unstimulated uninfected wells were treated with $250 \mu \mathrm{L} \mathrm{C10} \mathrm{media.} \mathrm{Plates}$ were incubated at $37^{\circ} \mathrm{C} 5 \% \mathrm{CO}_{2}$ for 48 hours, whereupon multiplexed ELISA (culture supernatants) and flow cytometry (PBMCs) were performed for the day 5 time point (48 hours post-HIV exposure).

\section{Flow cytometry}

Cellular activation of PBMCs at two time points (day 3: 48 hours poststimulation and prior to HIV exposure and day 5: 48 hours post-HIV exposure) was assessed by flow cytometry, focusing on CCR5, HLA-DR and CD38 expression by
CD4 + cells, as previously described, ${ }^{79-81}$ using both extracellular and intracellular staining. The extracellular staining cocktail consisted of LIVE/DEAD Amcyan fixable dye (Thermo Fisher Scientific, Waltham, Massachusetts, USA), anti-CD3-APC-H7, anti-CD4-BV605, anti-CD8-BV655, anti-CD14-pacific blue (all from BD Biosciences, Franklin Lakes, New Jersey, USA), and anti-CD19-pacific blue (BioLegend, San Diego, California, USA). The intracellular staining cocktail consisted of anti-CCR5-APC, anti-HLADR-PerCP-CY5.5 (all from BD Biosciences), anti-CD38PE-CY7 (BioLegend) and anti-p24-FITC (Beckman Coulter, Brea, California, USA).

To pellet the cells and remove soluble HIV, PBMCs were centrifuged at $3500 \mathrm{rpm}$ for $5 \mathrm{~min}$, and cell culture supernatants were stored at $-80^{\circ} \mathrm{C}$ for cytokine quantification. PBMCs were washed with sterile PBS supplemented with $2 \%$ FCS and then stained with $100 \mu \mathrm{L}$ extracellular staining cocktail, fixed, and then stained with $100 \mu \mathrm{L}$ intracellular staining cocktail. Data were acquired by flow cytometry on a BD LSR Fortessa (BD Biosciences), with $5 \times 10^{5}$ events within the lymphocyte gate collected per sample. Data analysis was performed using FlowJo V.10.4.1 software (Tree Star, Ashland, Oregon, USA). Online supplemental figure 1 shows the gating strategy from our previous publication ${ }^{77}$ and follows other published studies. ${ }^{82} 83$ In this study, we reported on four activation phenotypes (CD38+HLA-DR+, CD38+HLA-DR-, CD38-HLA-DR+, and CD38-HLA$\mathrm{DR}-)$ and define these as previously described. ${ }^{4780} \mathrm{CD} 4+$ T cells expressing CD38+HLA-DR + were defined as hyperactivated; the CD38+HLA-DR - and CD38-HLA-DR+ phenotypes were defined as intermediately activated; and CD38-HLA-DR-CD4+ T cells were defined as resting or not activated. Representative dot plots of flow cytometric data are shown in online supplemental figure 2.

\section{Cytokine quantification}

From cell culture supernatants, the concentrations of 28 cytokines were assessed using the Bio-Plex Pro Human Cytokine Group I 27-Plex Panel (Bio-Rad Laboratories, Hercules, CA, USA) and the Magnetic Luminex Assay IL-1 $\alpha$ Singleplex Kit (Research and Diagnostic Systems, Minneapolis, Minnesota, USA) as per manufacturer's instructions. Data were acquired on a Bio-Plex 200 system (Bio-Rad Laboratories). Standard curves were optimized using the Bio-Plex Manager V.6.1 software (Bio-Rad Laboratories). Values with coefficients of variation of $<20 \%$ and with observed recoveries between $70 \%$ and $130 \%$ were considered reliable. Values that were below the detectable limit were assigned half of the lowest limit of detection value, while values that were above the detectable limit were assigned double the highest limit of detection value.

\section{Statistical analyses}

GraphPad Prism V.7.02 software for Windows (GraphPad Software, La Jolla, California, USA) was used for statistical analyses and graphical representation of data. The ShapiroWilk normality test was performed to determine the distribution of the data. Cellular activation results are displayed as mean percentage $(\%) \pm \mathrm{SD}$ of CD4+ T cells. For comparisons of cellular activation markers CD38, HLA-DR on 


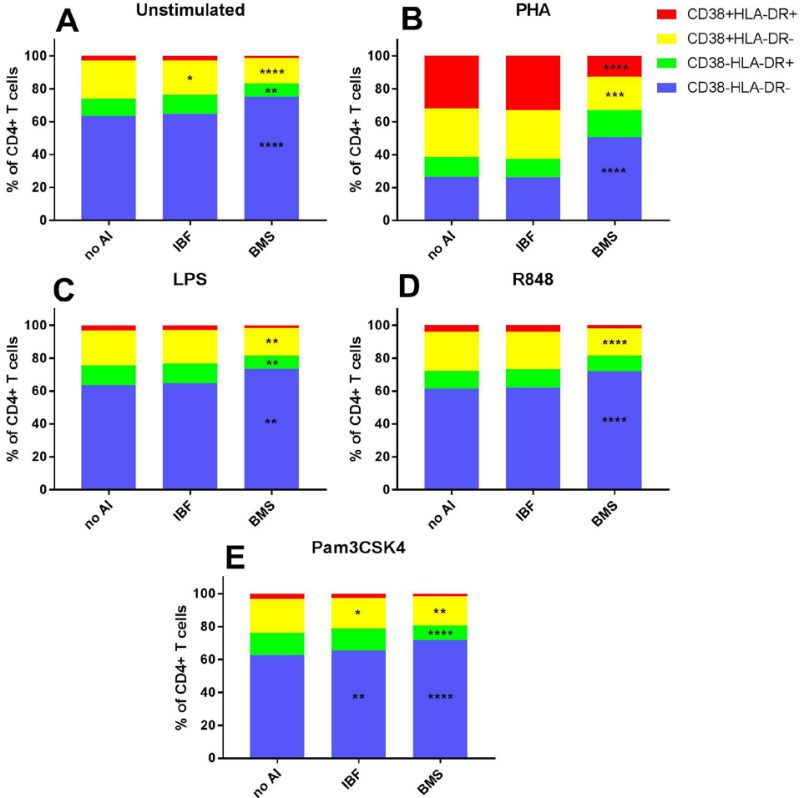

Figure 1 Activation profiles of CD4+T cells on day 3 prior to HIV exposure either treated with anti-inflammatory drugs IBF or BMS or left untreated (no $A I)$ and then either left unstimulated $(A)$ or stimulated with PHA (B), LPS (C), R848 (D) or Pam3CSK4 (E). PHA was used at a final concentration of $10 \mu \mathrm{g} / \mathrm{mL}$. TLR agonists were used at a final concentration of $2 \mu \mathrm{g} / \mathrm{mL}$. Al drugs IBF and BMS were both used at a final concentration of $1 \mu \mathrm{g} / \mathrm{mL}$. A repeated measures two-way analysis of variance with Dunnett's multiple comparison test was performed to assess significant differences between $\mathrm{Al}$ conditions within each stimulation condition. ${ }^{*} \mathrm{P}<0.05,{ }^{*} \mathrm{P}<0.01,{ }^{* *}{ }^{*} \mathrm{P}<0.001,{ }^{* * * *} \mathrm{P} \leq 0.0001$, compared with the untreated (no Al) control. Sample size, $n=4$, donors run in duplicate. Al, anti-inflammatory; BMS, betamethasone; IBF, ibuprofen; LPS, lipopolysaccharide; PHA, phytohemagglutinin; TLR, Toll-like receptor.

CD4+ T cells, between anti-inflammatory treated conditions and the untreated control, a repeated measures twoway analysis of variance (ANOVA) with Dunnett's multiple comparison test was performed. Similarly, an ordinary oneway ANOVA with Dunnett's multiple comparison test was performed for CCR5 expression and cytokine comparisons. Cytokine data were normalized by $\log _{10}$ transformation and are displayed as mean concentration $\left(\log _{10} \mathrm{pg} / \mathrm{mL}\right) \pm \mathrm{SD}$. Heat maps were generated by performing a single linkage hierarchical cluster analysis using R V.3.3.3 statistical software ( $\mathrm{R}$ Foundation for Statistical Computing, Vienna, Austria) to visualize the effect of various TLR agonists and anti-inflammatory drugs on cytokine expression. Radial spider plots were created using Microsoft Excel V.2013 software.

\section{RESULTS}

\section{Reduction of CD4+ T-cell activation by BMS but not IBF prior to HIV exposure}

As anti-inflammatory drugs can have cytotoxic effects, ${ }^{84}$ we sought to determine how IBF and BMS impacted on the viability of CD4+ T cells. Prior to HIV exposure (day 3), BMS was slightly toxic to unstimulated cells with a $7.6 \%$ reduction of viable cells $(p=0.02$, online supplemental figure $3 \mathrm{~A}$ ) but improved the number of viable cells stimulated with LPS by $9.2 \%(p=0.004)$ or $\mathrm{R} 848$ by $12.4 \%$ $(p=0.0001$, online supplemental figure 3C,D). Similarly, post-HIV exposure (day 5) BMS improved cellular viability in the LPS, R848 and Pam3CSK4-stimulated conditions $(\mathrm{p} \leq 0.0001$, online supplemental figure $4 \mathrm{C}-\mathrm{E})$.

We sought to determine how anti-inflammatory drugs IBF and BMS impacted the activation status of CD4+ T cells stimulated with TLR agonists, given that activated target cells have been shown to be preferentially infected with HIV $^{4243}$ and allow more proficient viral replication. ${ }^{85-87}$ TLR agonists LPS, R848 and Pam3CSK4 had a minimal impact on the activation of CD4 $+\mathrm{T}$ cells, unlike the positive control PHA (figure 1). IBF significantly reduced the frequency of intermediately activated CD38+HLA-DR - CD4 $+\mathrm{T}$ cells in the unstimulated $(\mathrm{p}=0.02)$ and Pam3CSK4-stimulated $(\mathrm{p}=0.02)$ conditions by $2.35 \%$ and $2.36 \%$, respectively (figure 1A-E). Decreases in this subset in the Pam3CSK4stimulated condition were concomitant with a significantly increased frequency of inactivated CD38-HLA-DR-CD4+ $\mathrm{T}$ cells, suggesting that IBF returned CD4 $+\mathrm{T}$ cells to their resting state $(p=0.009$, figure $1 \mathrm{E})$. A similar phenomenon is
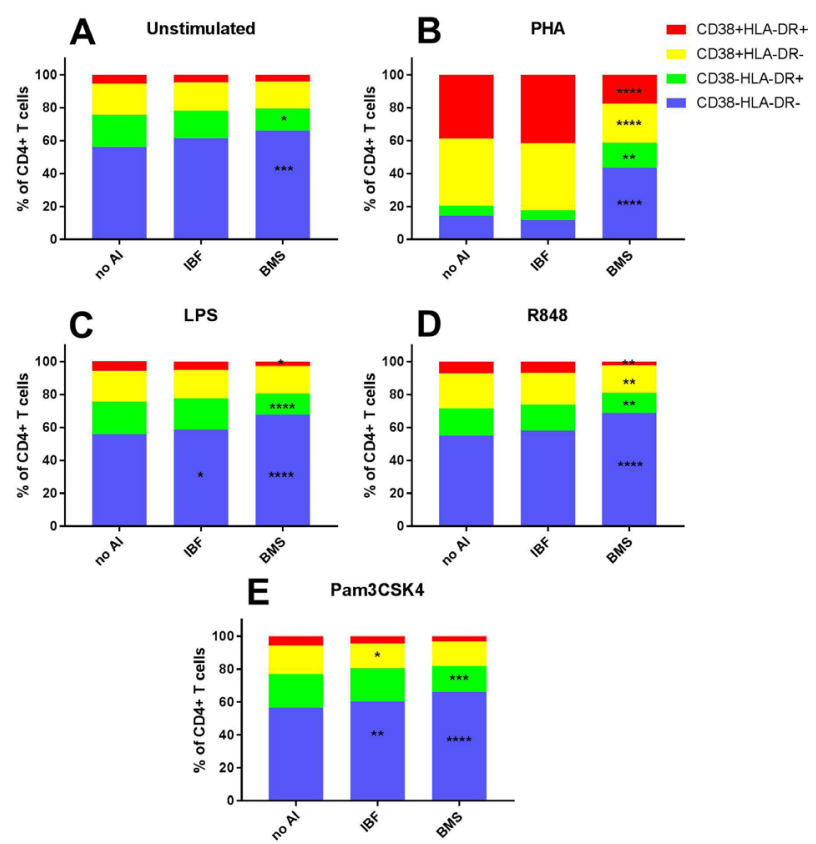

Figure 2 Activation profiles of CD4+ T cells on day 5 post-HIV exposure either treated with anti-inflammatory drugs IBF or BMS or left untreated (no $\mathrm{Al}$ ) and then either left unstimulated $(\mathrm{A})$ or stimulated with PHA (B), LPS (C), R848 (D) or Pam3CSK4 (E). PHA was used at a final concentration of $10 \mu \mathrm{g} / \mathrm{mL}$. TLR agonists were used at a final concentration of $2 \mu \mathrm{g} / \mathrm{mL}$. Al drugs IBF and BMS were both used at a final concentration of $1 \mu \mathrm{g} / \mathrm{mL}$. A repeated measures two-way analysis of variance with Dunnett's multiple comparison test was performed to assess significant differences between $\mathrm{Al}$ conditions within each stimulation condition.

${ }^{*} \mathrm{P}<0.05,{ }^{*} \mathrm{P}<0.01,{ }^{* *}{ }^{*} \mathrm{P}<0.001,{ }^{* * * * P} \leq 0.0001$, compared with the untreated (no AI) control. Sample size, $n=4$, donors run in duplicate. Al, anti-inflammatory; BMS, betamethasone; IBF, ibuprofen; LPS, lipopolysaccharide; PHA, phytohemagglutinin, TLR, Toll-like receptor. 
likely in the unstimulated condition, with a less pronounced increase in the resting CD4 $+\mathrm{T}$ cells. Compared with IBF, BMS had potent immunosuppressive effects on CD4+ T-cell activation, with increased frequencies of inactivated/resting CD38-HLA-DR-CD4+ $\mathrm{T}$ cells across all stimulation conditions ( $\mathrm{p} \leq 0.0001$, figure 1). As PHA induced significant cellular activation, the frequency of highly activated CD38 HLA-DR +CD4+ T cells was significantly reduced by $20.8 \%$ with BMS treatment ( $\leq \leq 0.0001$, figure $1 B$ ). Furthermore, a reduction in the frequency of CD38+HLA-DRCD4+ T cells was observed across all stimulation conditions $(\mathrm{p}<0.01$, figure 1$)$. Similarly, the frequency of CD38HLA-DR + CD4 $+\mathrm{T}$ cells were reduced in the unstimulated $(p=0.006)$, LPS-stimulated $(p=0.005)$ and Pam3CSK4stimulated $(\mathrm{p} \leq 0.0001)$ conditions by $2.78 \%, 3.8 \%$ and $4.48 \%$, respectively (figure $1 \mathrm{~A}, \mathrm{C}-\mathrm{E}$ ).

\section{Suppression of T-cell activation is maintained by BMS after HIV exposure}

Similar to the results observed prior to HIV exposure, IBF had minimal immunosuppressive effects in terms of hyperactivated CD4 $+\mathrm{T}$ cells, with only a modest $2.76 \%$ decrease in the frequency of intermediately activated $\mathrm{CD} 38+\mathrm{H}$ LA-DR-CD4+ $\mathrm{T}$ cells in the Pam3CSK4-stimulated condition $(p=0.04$, figure $2 \mathrm{E})$. Furthermore, an increased frequency of inactivated/resting CD38-HLA-DR-CD4+ T cells were observed in the LPS $(p=0.03)$ and Pam3CSK4stimulated $(\mathrm{p}=0.005)$ conditions by $2.7 \%$ and $3.71 \%$, respectively, following IBF treatment (figure $2 \mathrm{C}-\mathrm{E}$ ). As previously observed, BMS had more potent immunosuppressive activity than IBF, resulting in significantly lower frequencies of highly activated CD38+HLA-DR +CD4+ T cells following treatment with PHA $(\mathrm{p} \leq 0.0001)$, LPS $(\mathrm{p}=0.02)$ and R848 $(p=0.002)$ by $20.88 \%, 2.89 \%$ and $4.85 \%$, respectively (figure 2B-D). Additionally, BMS also resulted in significantly reduced frequencies of intermediately activated $\mathrm{CD} 38+\mathrm{H}$ LA-DR - CD4 + T cells following PHA $(\mathrm{p} \leq 0.0001)$ and R848 stimulation $(\mathrm{p}=0.004)$ by $17.2 \%$ and $4.5 \%$, respectively (figure 2B,D). Furthermore, significant reductions in the frequency of CD38-HLA-DR+CD4 + T cells $(p<0.05)$ and a significant increase in the frequency of CD38-HLA-DRCD4 + T cells $(p<0.001)$ were observed across all stimulation conditions (figure $2 \mathrm{~A}-\mathrm{E}$ ).

\section{Modulation of TLR-mediated CCR5 expression by BMS occurs only at the early time-point}

As CCR5 expression on CD4+ T cells is crucial for R5 tropic HIV infection, we sought to assess how the antiinflammatory drugs IBF and BMS impacted on CCR5 expression following TLR agonist stimulations. Prior to HIV exposure, BMS downregulated CCR5 expression on CD4+ $\mathrm{T}$ cells in TLR $(\mathrm{p}<0.02)$ and PHA-stimulated conditions ( $\mathrm{p} \leq 0.0001$ ) by $1 \%-1.5 \%$ and $11.5 \%$, respectively, while IBF had no impact (figure 3A). Following coculture with HIV, BMS-mediated downregulation of CCR5 following TLR stimulation was lost, while BMS-reduced CCR5 expression was observed in the unstimulated $(p=0.04)$ and PHA-stimulated $(\mathrm{p} \leq 0.0001)$ controls by $2.59 \%$ and $10.52 \%$, respectively (figure $3 \mathrm{~B}$ ).

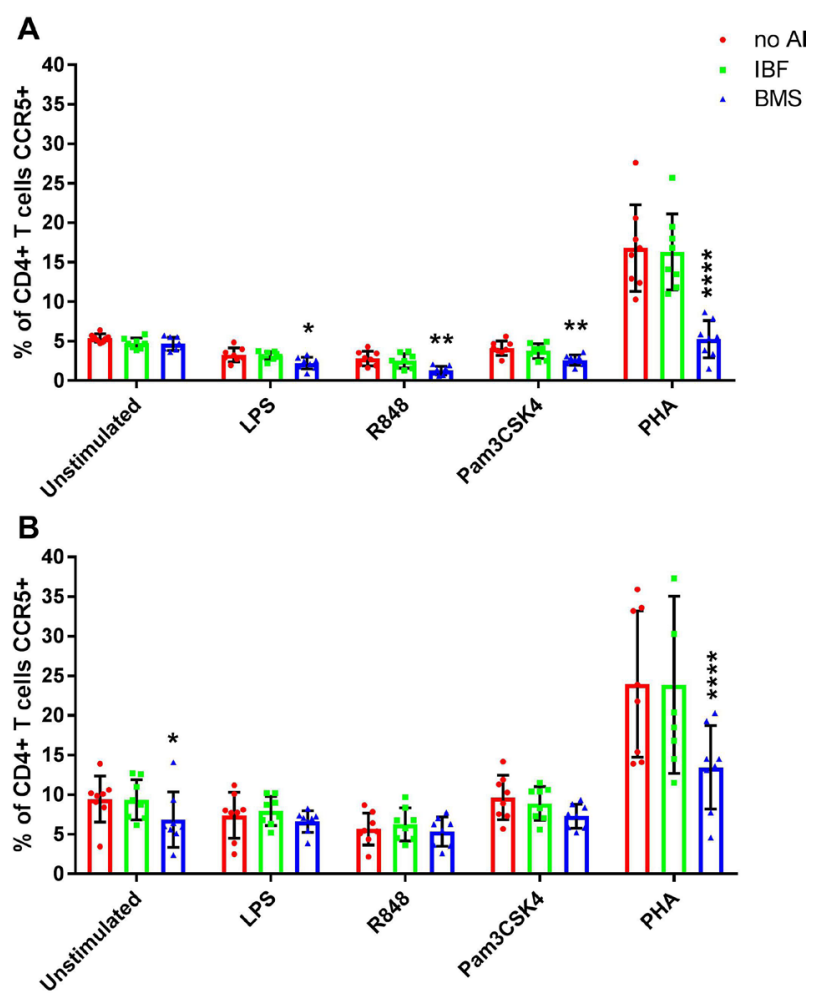

Figure 3 CCR5 expression on CD4+ T cells on day 3 prior to HIV exposure (A) or day 5 post-HIV exposure (B) either treated with anti-inflammatory drugs IBF (green) or BMS (blue) or left untreated (no Al, red) and then either left unstimulated or stimulated with PHA, LPS, R848 or Pam3CSK4. PHA was used at a final concentration of $10 \mu \mathrm{g} / \mathrm{mL}$. TLR agonists were used at a final concentration of $2 \mu \mathrm{g} / \mathrm{mL}$. Al drugs IBF and BMS were both used at a final concentration of $1 \mu \mathrm{g} / \mathrm{mL}$. An ordinary one-way analysis of variance with Dunnett's multiple comparison test was performed to assess significant differences between $\mathrm{Al}$ conditions within each stimulation condition. ${ }^{*} \mathrm{P}<0.05,{ }^{*} \mathrm{P}<0.01,{ }^{* * *}{ }^{*} \mathrm{P} \leq 0.0001$, compared with the untreated (no Al) control within each stimulation condition. Sample size, $n=4$, donors run in duplicate. $\mathrm{Al}$, anti-inflammatory; BMS, betamethasone; IBF, ibuprofen; LPS, lipopolysaccharide; PHA, phytohemagglutinin, TLR, Toll-like receptor.

\section{BMS treatment potently reduces global cytokine and chemokine secretion}

Unsupervised hierarchical clustering analysis showed a pattern that overall, concentrations of all cytokines were reduced with BMS treatment compared with the untreated and IBF-treated conditions (online supplemental figure 5).

Prior to HIV exposure (day 3), concentrations of interleukin (IL)-1 $\alpha$ were significantly increased by $0.45 \log _{10} \mathrm{pg} /$ $\mathrm{mL}$ with IBF treatment compared with the untreated control in the unstimulated condition $(p=0.03$, figure $4 \mathrm{~A})$. Conversely, BMS reduced IL- $1 \alpha$ levels in both the TLR$(\mathrm{p}<0.005)$ and PHA-stimulated $(\mathrm{p} \leq 0.0001)$ conditions by $0.6-1.78$ and $1.5 \log _{10} \mathrm{pg} / \mathrm{mL}$, respectively (figure 4A). Similarly, BMS significantly reduced IL-1 $\beta$ ( $\mathrm{p} \leq 0.0001)$, IL-6 $(p<0.01)$, IL-12(p70) $(p \leq 0.0001)$ and tumor necrosis factor alpha $(T N F-\alpha) \quad(p \leq 0.0001)$ compared with the untreated control for all conditions (figure 4B-D,F). Furthermore, interferon (IFN) $-\gamma$ production was also significantly reduced 

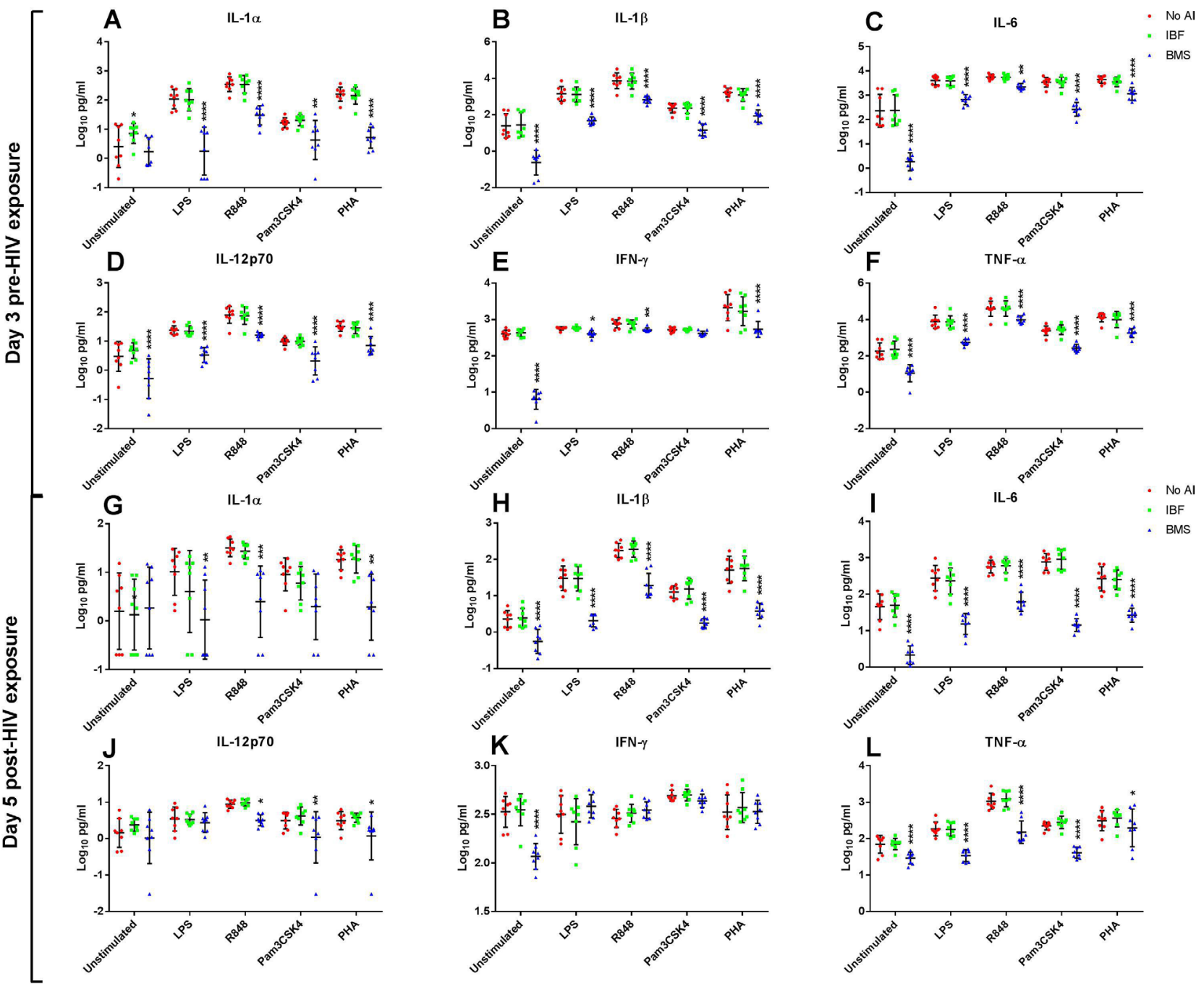

Figure 4 Box and whisker plots showing mean $\pm S D \log _{10}$ concentrations of soluble proinflammatory cytokines IL-1 $\alpha(A, G), I L-1 \beta(B, H)$, IL-6 (C,I), IL-12p70 (D,J), IFN- $\gamma(E, K)$ and TNF- $\alpha(F, L)$ from PBMCs either left untreated (no Al, red) or treated with anti-inflammatory drugs IBF (green) or BMS (blue) and then either left unstimulated or stimulated with LPS, R848, Pam3CSK4 or PHA on day 3 prior to HIV exposure $(A-F)$ and day 5 post-HIV exposure $(G-L)$. PHA was used at a final concentration of $10 \mu \mathrm{g} / \mathrm{mL}$. TLR agonists were used at a final concentration of $2 \mu \mathrm{g} / \mathrm{mL}$. Both IBF and BMS were used at $1 \mu \mathrm{g} / \mathrm{mL}$. An ordinary one-way analysis of variance with Dunnett's multiple comparison test was performed to assess significant differences between Al conditions within each stimulation condition. ${ }^{*} \mathrm{P}<0.05$, ${ }^{*} \mathrm{P}<0.01,{ }^{* *} \mathrm{P}<0.001,{ }^{* * * *} \mathrm{P} \leq 0.0001$, compared with the untreated (no Al) control. Sample size, $\mathrm{n}=4$, donors run in duplicate. Al, antiinflammatory; BMS, betamethasone; IBF, ibuprofen; IFN, interferon; IL, interleukin; LPS, lipopolysaccharide; PHA, phytohemagglutinin; PBMC, peripheral blood mononuclear cell; TLR, Toll-like receptor; TNF- $\alpha$, tumor necrosis factor alpha.

by BMS in the unstimulated $(\mathrm{p} \leq 0.0001)$, LPS-stimulated $(\mathrm{p}=0.02), \mathrm{R} 848$-stimulated $(\mathrm{p}=0.005)$ and PHA-stimulated $(\mathrm{p} \leq 0.0001)$ conditions by $1.8,0.15,0.17$ and $0.6 \log _{10} \mathrm{pg} /$ $\mathrm{mL}$, respectively (figure 4E). After HIV exposure (day 5), BMS treatment reduced IL- $1 \alpha$ levels in the LPS-stimulated $(\mathrm{p}=0.003), \quad \mathrm{R} 848$-stimulated $(\mathrm{p}=0.0008)$ and PHAstimulated $(\mathrm{p}=0.003)$ conditions by $0.99,1.11$ and 0.98 $\log _{10} \mathrm{pg} / \mathrm{mL}$, respectively, but not the Pam3CSK4 condition, compared with the untreated control (figure 4G). Consistent with the results prior to HIV exposure, the levels of IL-1 $\beta(p \leq 0.0001)$, IL-6 $(p \leq 0.0001)$ and TNF- $\alpha(p=0.03)$ were reduced with BMS treatment compared with the untreated cells, across all conditions (figure 4H,I,L). Similarly, BMS dampened the production of IL-12(p70) in R848stimulated $(\mathrm{p}=0.01)$, Pam3CSK4-stimulated $(\mathrm{p}=0.008)$ and
PHA-stimulated $(\mathrm{p}=0.02)$ conditions by $0.45,0.46$ and 0.42 $\log _{10} \mathrm{pg} / \mathrm{mL}$, respectively, while IFN- $\boldsymbol{\gamma}$ was also dampened in the unstimulated condition $(\mathrm{p} \leq 0.0001)$ by $0.46 \log _{10} \mathrm{pg} / \mathrm{mL}$ (figure 4J,K).

Similar to the proinflammatory cytokines, BMS significantly reduced IL- $8(\mathrm{p} \leq 0.0001)$, macrophage inflammatory protein (MIP)-1 $\alpha(\mathrm{p}<0.05)$, MIP-1 $\beta(\mathrm{p} \leq 0.0001)$ and interferon gamma-induced protein-10 (IP-10) $(\mathrm{p}<0.005)$ production in all conditions compared with the untreated control, prior to HIV exposure (figure 5A-D). Furthermore, monocyte chemoattractant protein-1 (MCP-1) was reduced by 2.12 $\log _{10} \mathrm{pg} / \mathrm{mL}$ following BMS treatment in the unstimulated condition only $(\mathrm{p}<0.0001$, figure $5 \mathrm{E})$. Regulated upon activation, normal T cell expressed and secreted (RANTES) production was also significantly reduced following BMS treatment 

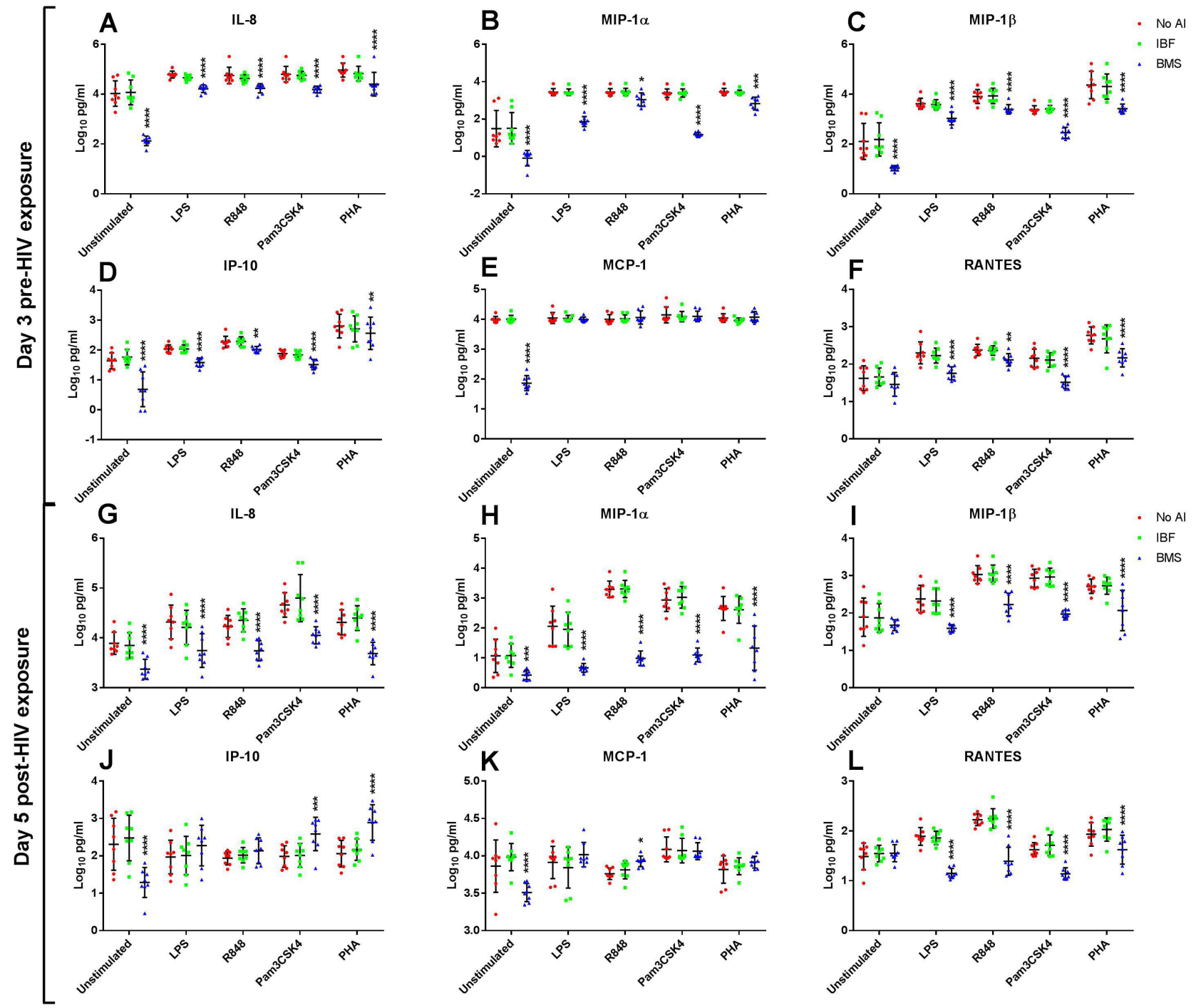

Figure 5 Box and whisker plots showing mean $\pm S D \log _{10}$ concentrations of soluble chemotactic cytokines IL-8 (A,G), MIP-1 $\alpha(B, H)$, MIP-1 $\beta(C, I), I P-10(D, J)$, MCP-1 $(E, K)$ and RANTES $(F, L)$ from PBMCs either left untreated (no Al, red) or treated with anti-inflammatory drugs IBF (green) or BMS (blue) and then either left unstimulated or stimulated with LPS, R848, Pam3CSK4 or PHA on day 3 prior to HIV exposure $(A-F)$ and day 5 post-HIV exposure (G-L). PHA was used at a final concentration of $10 \mu \mathrm{g} / \mathrm{mL}$. TLR agonists were used at a final concentration of $2 \mu \mathrm{g} / \mathrm{mL}$. Both IBF and BMS were used at $1 \mu \mathrm{g} / \mathrm{mL}$. An ordinary one-way analysis of variance with Dunnett's multiple comparison test was performed to assess significant differences between Al conditions within each stimulation condition. ${ }^{*} \mathrm{P}<0.05$, ${ }^{* *} \mathrm{P}<0.01,{ }^{* *} \mathrm{P}<0.001,{ }^{* * *} \mathrm{P} \leq 0.0001$, compared with the untreated (no Al) control. Sample size, $\mathrm{n}=4$, donors run in duplicate. Al, antiinflammatory; BMS, betamethasone; IBF, ibuprofen; IL, interleukin; IP-10, interferon gamma-induced protein-10; LPS, lipopolysaccharide; MCP-1, monocyte chemoattractant protein-1; MIP-1 $\beta$, macrophage inflammatory protein-1 $\beta$; PHA, phytohemagglutinin; PBMC, peripheral blood mononuclear cell; RANTES, regulated upon activation, normal T cell expressed and secreted; TLR, toll-like receptor.

in all the TLR- $(\mathrm{p} \leq 0.002)$ and PHA-stimulated $(\mathrm{p} \leq 0.0001)$ conditions by $0.26-0.64$ and $0.6 \log _{10} \mathrm{pg} / \mathrm{mL}$ compared with the untreated controls (figure 5F). Similarly, post-HIV exposure, IL- $8(\mathrm{p} \leq 0.0001)$ and MIP-1 $\alpha(\mathrm{p} \leq 0.001)$ levels were significantly reduced with BMS treatment compared with the untreated control across all conditions (figure 5G,H). Furthermore, MIP-1 $\beta$ and RANTES levels were significantly reduced following BMS treatment compared with the untreated control in the TLR-stimulated and PHA-stimulated conditions after HIV exposure $(\mathrm{p} \leq 0.0001$, figure 5I,L). Similarly, MCP-1 levels were significantly reduced with BMS treatment by $0.35 \log _{10} \mathrm{pg} / \mathrm{mL}$ compared with the untreated control in the unstimulated condition $(\mathrm{p} \leq 0.0001)$. However,
BMS treatment increased MCP-1 levels produced in response to $\mathrm{R} 848$ stimulation by $0.17 \log _{10} \mathrm{pg} / \mathrm{mL}$ compared with untreated cells $(p=0.02$, figure $5 K)$. IP-10 levels were significantly reduced in the unstimulated condition by 1.02 $\log _{10} \mathrm{pg} / \mathrm{mL}(\mathrm{p} \leq 0.0001)$, while they were increased in the Pam3CSK4-stimulated $(\mathrm{p}=0.0002)$ and PHA-stimulated $(\mathrm{p} \leq 0.0001)$ conditions by 0.6 and $0.84 \log _{10} \mathrm{pg} / \mathrm{mL}$, respectively, with following BMS treatment compared with the untreated control (figure 5J).

Regulatory cytokines like IL-17 are secreted primarily by Th17 cells that maintain mucosal barrier homeostasis. $^{88-90}$ Prior to HIV exposure, regulatory cytokines IL-17 and granulocyte-macrophage colony-stimulating factor 


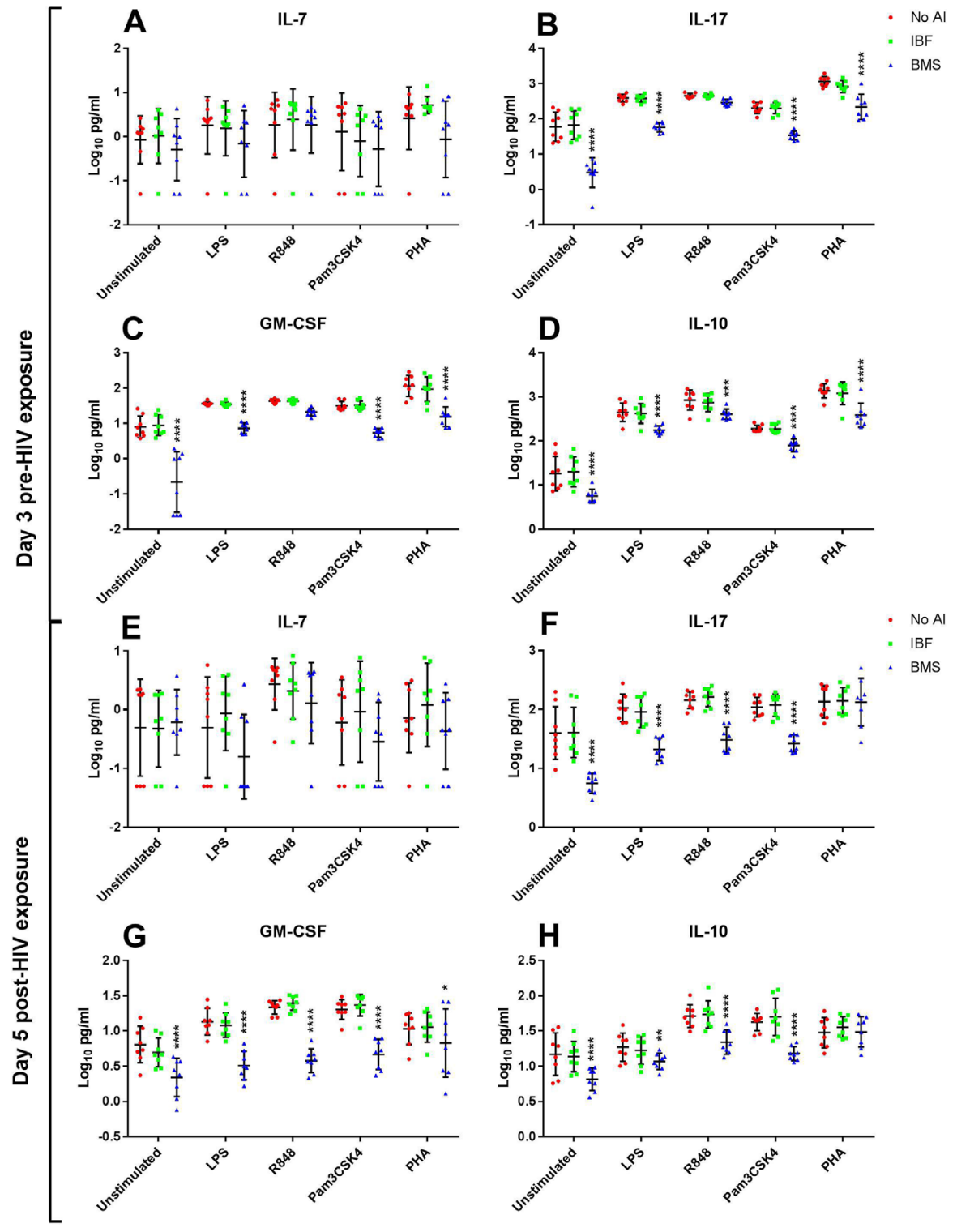

Figure 6 Box and whisker plots showing mean $\pm S D \log _{10}$ concentrations of soluble haematopoietic cytokines IL-7 (A,E) and IL-17 (B,F), the growth factor GM-CSF $(C, G)$ and the anti-inflammatory cytokine IL-10 $(D, H)$ from PBMCs either left untreated (no Al, red) or treated with anti-inflammatory drugs IBF (green) or BMS (blue) and then either left unstimulated or stimulated with LPS, R848, Pam3CSK4 or PHA on day 3 prior to HIV exposure (A-D) and day 5 post-HIV exposure (E-H). PHA was used at a final concentration of $10 \mu \mathrm{g} / \mathrm{mL}$. TLR agonists were used at a final concentration of $2 \mu \mathrm{g} / \mathrm{mL}$. Both IBF and BMS were used at $1 \mu \mathrm{g} / \mathrm{mL}$. An ordinary one-way analysis of variance with Dunnett's multiple comparison test was performed to assess significant differences between Al conditions within each stimulation condition. ${ }^{*} \mathrm{P}<0.05$, ${ }^{* *} \mathrm{P}<0.01$, ${ }^{* *} \mathrm{P}<0.001$, ${ }^{* * *} \mathrm{P} \leq 0.0001$, compared with the untreated (no Al) control. Sample size, $\mathrm{n}=4$, donors run in duplicate. Al, anti-inflammatory; BMS, betamethasone; CM-CSF, granulocyte-macrophage colony-stimulating factor; IBF, ibuprofen; IL, interleukin; LPS, lipopolysaccharide; PHA, phytohemagglutinin; PBMC, peripheral blood mononuclear cell; TLR, Toll-like receptor.

(GM-CSF) levels were reduced following BMS treatment compared with the untreated control in the unstimulated condition by 1.3 and $1.57 \log _{10} \mathrm{pg} / \mathrm{mL}$, and conditions stimulated with LPS by 0.83 and $0.7 \log _{10} \mathrm{pg} / \mathrm{mL}$, Pam3CSK 4 by 0.78 and $0.78 \log _{10} \mathrm{pg} / \mathrm{mL}$, and PHA by 0.72 and $0.87 \log _{10} \mathrm{pg} /$ $\mathrm{mL}(\mathrm{p} \leq 0.0001$, figure $6 \mathrm{~B}, \mathrm{C})$. Similarly, IL-10 levels were also significantly reduced with BMS treatment compared with the untreated control across all conditions ( $p<0.001$, figure 6D). Post-HIV exposure, IL-17 and IL-10 levels were still reduced with BMS treatment compared with the untreated control in the unstimulated $(\mathrm{p} \leq 0.0001)$ and TLR-stimulated $(\mathrm{p} \leq 0.009)$ conditions (figure 6F,H). Additionally, GM-CSF levels were reduced with BMS treatment compared with the untreated control across all conditions ( $p<0.05$, figure $6 \mathrm{G})$.

\section{BMS-mediated reduction of HIV infection occurs in the unstimulated and LPS-stimulated conditions}

Significant reductions of HIV infections were found in the BMS-treated unstimulated $(\mathrm{p}=0.0002)$ and LPS-stimulated $(\mathrm{p}=0.02)$ conditions by $1.7 \%$ and $0.98 \%$, respectively, compared with the untreated control (figure 7A,C). No 


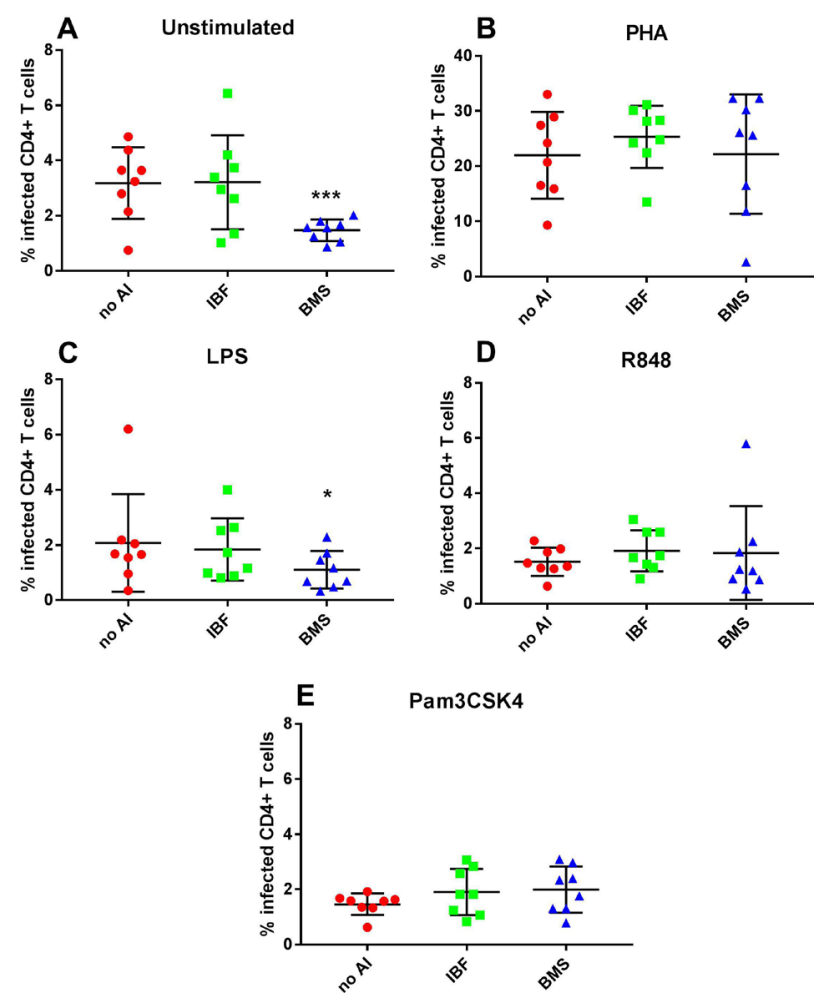

Figure 7 Frequency of HIV-infected CD4+ T cells (measured by p24 expression) either left untreated (no Al, red) or treated with anti-inflammatory drugs IBF (green) or BMS (blue) and then either left unstimulated (A) or stimulated with PHA (B), LPS (C), R848 (D) or Pam3CSK4 (E). PHA was used at a final concentration of $10 \mu \mathrm{g} / \mathrm{mL}$. TLR agonists were used at a final concentration of $2 \mu \mathrm{g} / \mathrm{mL}$. Both IBF and BMS were used at $1 \mu \mathrm{g} / \mathrm{mL}$. An ordinary one-way analysis of variance with Dunnett's multiple comparison test was performed to assess significant differences between Al conditions within each stimulation condition. ${ }^{*} P<0.05$, ${ }^{* * *} \mathrm{P}<0.001$, compared to the untreated (no Al) control. Sample size, $n=4$, donors run in duplicate. Al, anti-inflammatory; BMS, betamethasone; IBF, ibuprofen; LPS, lipopolysaccharide; PHA, phytohemagglutinin; PBMC, peripheral blood mononuclear cell; TLR, Toll-like receptor.

significant differences were observed with BMS treatment in the PHA-stimulated, R848-stimulated or Pam3CSK4stimulated conditions ( $p>0.05$; figure $7 B, D, E$ ), suggesting some differential interactions occurring in the unstimulated and LPS-stimulated conditions as opposed to the PHAstimulated, R848-stimulated and Pam3CSK4-stimulated conditions with BMS. Additionally, no significant differences in HIV infection were observed with IBF treatment in any of the stimulation conditions ( $p>0.05$, figure 7 ).

\section{DISCUSSION}

Genital inflammation is associated with increased HIV acquisition risk, ${ }^{141647}$ while immune quiescence is an established correlate of protection for reduced risk in HESN populations. ${ }^{649192}$ Therefore, the utility of immunomodulatory drugs to augment immune quiescence is attractive to reduce HIV susceptibility. Using a PBMC-based culture system, this study aimed to investigate the effect of two licensed anti-inflammatory drugs, the GC BMS and the
NSAID IBF, in limiting TLR-induced inflammatory cytokine productions, cellular activation and susceptibility to HIV infection. While IBF demonstrated only modest immunosuppression and no anti-inflammatory or anti-HIV activity in this model, BMS showed potent immunosuppression and anti-inflammatory effects, with reduced HIV infection.

Consistent with our previous findings, ${ }^{77}$ TLR2 (Pam3CSK4) and TLR4 (LPS) stimulation did not induce significant CD4+ Tcell activation, while TLR7/8 (R848) activation was moderately more effective. PHA induced the greatest cellular activation, likely due to activation of the T-cell receptor (TCR) on CD4 + T cells. ${ }^{93}$ All TLR agonists induced a strong proinflammatory cytokine response at day 3, with R848 inducing the strongest inflammatory response over time. ${ }^{77}$ PHA induced a similar proinflammatory profile with higher concentrations of growth factor, anti-inflammatory and adaptive responses, and chemokines (IP-10, MIP-1 $\beta$ and RANTES). ${ }^{77}$

With IBF treatment, minimal immunosuppressive effects were observed, with small reductions in frequencies of intermediately activated CD38+HLA-DR-CD4 $+\mathrm{T}$ cells in the unstimulated and Pam3CSK4-stimulated conditions. Furthermore, IBF treatment had no discernible impact on frequencies of T cells expressing CCR5. This lack of immunosuppression may be attributed to $\mathrm{T}$ cells being unable to produce prostaglandins, likely a result of non-functional cyclooxygenase (COX) enzymes. ${ }^{94} 95$ However, conflicting data show NSAID reduced T-cell activation through the inhibition of COX enzymes, resulting in blocking of TCR-dependent p38 MAPK activation. ${ }^{96}$ Therefore, IBF may have interfered with the signaling pathways involved in immune activation in the unstimulated and Pam3CSK4-stimulated conditions here. Lajoie et al showed reduced levels of systemic and mucosal HIV target and Th17 cells in women treated with oral ASA daily for 6 weeks, while HCQ, mimicking the regime of ASA, reduced systemic CD4+CCR5 + and Th17 cells. Additionally, they showed that mucosal Th17 cells expressed lower CCR5 and CD69 following ASA treatment, ${ }^{68}$ highlighting that such commonly used NSAIDS may be effective in mitigating immune activation in vivo. IBF treatment had no effect on cytokine production here, in contrast to observations of reduced IL-1 $\beta$ and IL- 6 levels a human skin model ${ }^{97}$ and similar findings of reduced systemic inflammatory cytokines with oral ASA and HCQ. ${ }^{68}$ Conversely, in human PBMCs, IBF enhanced TNF- $\alpha$, IL- 6 and IL-1 $\beta$, but inhibited IL-1RA and IL-10, ${ }^{98}$ while ASA augmented IL-2 and IFN- $\gamma .{ }^{99}$ These data highlight the complex and heterogeneous immune profiles associated with different drugs. IBF had no effect on HIV infection, regardless of the stimulation conditions, whereas CQ, an NSAID, limited HIV replication in CD4+ $\mathrm{T}$ cells both in vitro and in vivo through limiting dendritic cell-specific intercellular adhesion molecule-3-grabbing nonintegrin (DC-SIGN)-mediated viral transfer to CD4+ T cells. $^{100}$

Unlike IBF, BMS had potent immunosuppressive and anti-inflammatory effects. CCR5 expression on CD4+ T cells was reduced by BMS prior to HIV exposure in all stimulated conditions, and the mechanisms underlying reduced CCR5 expression remain undefined. However, the effect of BMS reducing CCR5 expression in all TLR-stimulated conditions was lost after HIV exposure. Similarly, others also showed that GC treatment resulted in dramatic reduction 
of renal CCR5 $+\mathrm{CD} 3+\mathrm{T}$ cells. ${ }^{101}$ In contrast, upregulation of the chemokine receptor CCR2 (which binds MCP) was found on human monocytes with GC treatment, leading to increased HIV susceptibility. ${ }^{102}$ CCR2, like CCR5, has been shown to have functional importance for HIV infection and disease progression by acting as a coreceptor for HIV. ${ }^{103-106}$ However, the heterogenous effects of BMS on CCR5 expression before and after HIV exposure were unexpected, and the mechanisms underlying these differential effects need to be elucidated. Therefore, these findings necessitate the characterization of HIV coreceptor expression on target $\mathrm{T}$ cells especially if GC therapy is proposed as a means to mitigate HIV acquisition risk. BMS displayed potent immunosuppression and anti-inflammatory effects in all stimulation conditions, likely through the interference of gene transcription and signaling pathways. ${ }^{107-110}$ BMS was generally less effective with PHA stimulation, likely due to robust TCR activation by PHA. ${ }^{111}$ In concordance with our data, human studies have shown that GCs effectively reduced inflammatory cytokines. ${ }^{112-115}$ In contrast, Frank et al found that pretreatment with GCs, prior to LPS challenge, augmented inflammatory cytokine production (TNF- $\alpha$, IL-1 $\beta$ and IL-6). ${ }^{116}$ However, when GCs were administered post-LPS challenge, the inflammation was supressed, suggesting the temporal dynamics of anti-inflammatory action is likely to be important in determining their potency. ${ }^{116}$ These results suggest that there is differential sensitivity to GCs, which may be tissue-specific or compartment-specific. Another postulate for the immunoregulatory mechanism of GCs is the upregulated transcription of anti-inflammatory genes, such as IL-10, via the GC receptor ${ }^{117-119}$ and increased soluble IL-10 concentrations. ${ }^{114} 115$ However, in our study, IL-10 production was reduced by BMS treatment, consistent with the global antiinflammatory effects of GCs. BMS likely inhibited TLRmediated induction of gene expression through nuclear factor kappa-light-chain-enhancer of activated B cells (NF- $\mathrm{kB}$ ) or AP-1 blockade by the GC receptor. ${ }^{120} 121$ GCs have been shown to impact HIV replication by interfering with viral transcription, mediated through the GC receptor. ${ }^{122}$ In the unstimulated and LPS-stimulated conditions only, BMS likely inhibited NF- $\kappa \beta$-mediated gene transcription, which reduced HIV infection, whereas R848 and Pam3CSK4 agonists likely use different signaling pathways ${ }^{123}$ or have compensatory pathways with redundant functions. Despite the effective immunosuppression by BMS in the PHA condition, no impact on HIV infection was observed.

Our model system has some limitations that need to be acknowledged. ${ }^{77}$ We used a PBMC model instead of a vaginal epithelial cell line or ex vivo samples such as cervical mononuclear cells or explants. Despite inherent deficiencies with this model, PBMCs are more biologically representative than cell lines, depleted or purified immune cell models or explants, which are notoriously difficult to obtain and standardize. ${ }^{49} 124125$ PBMCs contain both peripheral and trafficked cells to or from tissues, and the activation status of these cells correlated between these compartments. ${ }^{79}$ A further limitation was the lack of cellular activation and minimal HIV infection observed following TLR stimulation. In contrast, the PHA stimulated model showed higher HIV infection, as activated $\mathrm{T}$ cells are more efficiently and preferentially infected. ${ }^{42-44}$ However, strong inflammatory cytokine responses were induced by TLR agonists, highlighting their roles in initiating inflammation to drive immunity. In the genital tract, continuous TLR stimulation by pathogenic microbes drive immune activation and genital inflammation, ${ }^{59}$ which is associated with increased HIV risk. ${ }^{14} 126$ To simulate similar conditions in a PBMC model, future experiments should include a TCR activator, such as antiCD3 and anti-CD28 beads, to mimic antigen presentation in combination with TLR stimulation to provide more robust immune activation. The TCR-activated model may be more appropriate for testing of anti-inflammatory drugs for their effects on immunosuppression and subsequent HIV infection. A further limitation was despite the potent immunosuppression by BMS in the PHA condition, there were no reductions in HIV infections, and we postulate that BMS impacts HIV infection independently of immunosuppression. This concept is reflected by the reduced HIV infection with BMS in the LPS and unstimulated conditions. Insight into the action of BMS on the GC receptor and HIV transcription pathways, may give clarity into the mechanisms of reduced HIV infection in these two conditions. While IBF effects were inferior to BMS, which we speculate may be related to the anti-inflammatory pathways for each anti-inflammatory drug target, we did not measure levels of COX enzymes, prostaglandins or signaling proteins to verify possible mechanisms responsible for IBF's relative inferior immunosuppressive and anti-inflammatory capabilities. While it would have been interesting to investigate in more depth the temporal impact of anti-inflammatory drugs in relation to HIV coculture, our study focused on pretreatment with anti-inflammatory drugs prior to stimulation. In so doing, we endeavored to identify plausible drug candidates to mitigate genital inflammation in populations at increased risk for HIV acquisition. This approach has precedence given that glycerol monolaurate, a topically applied vaginal microbicide, reduced inflammation and prevented SIV infections in rhesus macaques. ${ }^{45}{ }^{76}$ Both BMS and IBF are also licensed as topical formulations, ${ }^{74} 75127128$ making them attractive drug candidates. However, we acknowledge that long-term use of anti-inflammatory drugs does have unwanted and off-target adverse effects ${ }^{129-132}$ that should be considered. Topical anti-inflammatory formulations may be subject to the same limitations of adherence that undermined topical PrEP. ${ }^{12}$ However, various HIV prevention options need to be explored to accommodate the varying and changing needs of the HIV-affected communities.

To our knowledge, this is the first study investigating the effects of NSAIDs or GC treatment on HIV infection using an in vitro model. Other studies have investigated the effects of these drugs on inflammation/immune activation and HIV-mediated immune activation/replication in disease progression. This study provides important information on NSAID and GC effects on TLR-mediated immune responses and HIV infection, as well as underscoring the need to interrogate the inflammatory signaling pathways to identify novel drug targets. Together, these data may inform on the use of anti-inflammatory drug candidates as adjunctive prophylactic therapies in high-risk populations for HIV.

\section{Author affiliations}

${ }^{1}$ Mucosal Immunology Laboratory, CAPRISA, Durban, KwaZulu-Natal, South Africa

${ }^{2}$ Africa Health Research Institute (AHRI), Durban, KwaZulu-Natal, South Africa ${ }^{3}$ Max-Planck-Institute for Infection Biology, Berlin, Germany 
${ }^{4}$ Department of Medical Microbiology, University of KwaZulu-Natal, Durban, KwaZulu-Natal, South Africa

${ }^{5}$ Department of Medical Microbiology and Infectious Diseases, University of Manitoba, Winnipeg, Manitoba, Canada

${ }^{6}$ Department of Epidemiology, Columbia University Mailman School of Public Health, New York, New York, USA

${ }^{7}$ Institute of Infectious Diseases and Molecular Medicine, University of Cape Town Faculty of Health Sciences, Cape Town, Western Cape, South Africa

Acknowledgements Acknowledgements are reserved for present and past members of the Sigal Laboratory, including Dr Gila Lustig, Dr Mikaël Boullé and Ms Yashica Ganga for providing laboratory space and scientific expertise throughout this project. We thank the members of the CAPRISA statistics department, including Dr Nonhlanhla Yende and Mr Mesuli Mhlongo for insight into the statistical analysis of data generated by this project. A special thanks to the volunteers who donated blood during this study.

Contributors SSAK, JSP, LJL, LRM and DA acquired funding for the study and edited the manuscript. LJL, LRM, JSP, AS and DA assisted in the study design and analysis of data. RC designed and ran experimental procedures, acquired and analyzed data, and wrote and edited the manuscript. AS assisted in the study design, provided laboratory space for experimental procedures and edited the manuscript.

Funding RC, LJL, LRM, SSAK, JSP and DA and the experimental work were supported by a grant from the National Institutes of Health/National Institute of Allergy and Infectious Diseases (NIH/NIAID) R01 (grant number1R01Al111936-01). RC received support from the CAPRISA Research Administration and Management Training Program grant from the $\mathrm{NIH} /$ NIAID (grant number G11 TW010555-01). DA was supported through the Medical Research Council of South Africa Self-Initiated Grant, the National Research Foundation (NRF) of South Africa Thuthuka (grant number TTK160517165310), the NRF Research Career Advancement Fellowship (grant number RCA13101656388) and a senior fellowship through the European and Developing Countries Clinical Trials Partnership (grant number TMA2017SF-1960) funds. AS and part of the experimental work were also supported by the Max Planck Research Group Leader award (award number 74451011). LJ received support from a South African NRF Research Career Advancement Fellowship award, SANTHE Path to Independence award, and by a Future Leaders - African Independent Research (FLAIR) Fellowship supported by the African Academy of Sciences and the Royal Society.

Competing interests None declared.

Patient consent for publication Not required.

Ethics approval This study was approved by the University of KwaZuluNatal Biomedical Research Ethics Committee (ethics number BE433/14), with written informed consent from all healthy blood donors included in a volunteer donor blood study (ethics number BE022/13). Informed consent was obtained from all donors in accordance with the Declaration of Helsinki.

Provenance and peer review Not commissioned; externally peer reviewed.

Data availability statement Data are available upon reasonable request. The datasets generated for this study are available on request to the corresponding author.

Open access This is an open access article distributed in accordance with the Creative Commons Attribution Non Commercial (CC BY-NC 4.0) license, which permits others to distribute, remix, adapt, build upon this work noncommercially, and license their derivative works on different terms, provided the original work is properly cited, an indication of whether changes were made, and the use is non-commercial. See: http://creativecommons.org/ licenses/by-nc/4.0/.

\section{ORCID iD}

Ross Cromarty http://orcid.org/0000-0001-6386-615X

\section{REFERENCES}

1 UNAIDS. Facts sheet. Geneva, Switzerland: The Joint United Nations Programme on HIVIAIDS, 2018.

2 UNAIDS. AIDSinfo MAP Geneva. Switzerland: The Joint United Nations Programme on HIVIAIDS, 2018. http://aidsinfo.unaids.org/

3 Grant RM, Lama JR, Anderson PL, et al. Preexposure chemoprophylaxis for HIV prevention in men who have sex with men. N Engl J Med 2010;363:2587-99.

4 Molina J-M, Capitant C, Spire B, et al. On-Demand preexposure prophylaxis in men at high risk for HIV-1 infection. N Eng/ J Med 2015;373:2237-46.
5 McCormack S, Dunn DT, Desai M, et al. Pre-Exposure prophylaxis to prevent the acquisition of HIV-1 infection (PROUD): effectiveness results from the pilot phase of a pragmatic open-label randomised trial. The Lancet 2016;387:53-60.

6 Huang X, Hou J, Song A, et al. Efficacy and safety of oral TDF-Based preexposure prophylaxis for men who have sex with men: a systematic review and meta-analysis. Front Pharmacol 2018;9:799.

7 Abdool Karim Q, Abdool Karim SS, Frohlich JA, et al. Effectiveness and safety of tenofovir gel, an antiretroviral microbicide, for the prevention of HIV infection in women. Science 2010;329:1168-74.

8 Van Damme L, Corneli A, Ahmed K, et al. Preexposure prophylaxis for HIV infection among African women. N Engl J Med 2012;367:411-22.

9 Thigpen MC, Kebaabetswe PM, Paxton LA, et al. Antiretroviral preexposure prophylaxis for heterosexual HIV transmission in Botswana. N Engl J Med 2012;367:423-34.

10 Baeten JM, Donnell D, Ndase P, et al. Antiretroviral prophylaxis for HIV prevention in heterosexual men and women. N Engl J Med 2012;367:399-410.

11 Marrazzo JM, Ramjee G, Richardson BA, et al. Tenofovir-based preexposure prophylaxis for HIV infection among African women. N Engl J Med 2015;372:509-18.

12 Koenig LJ, Lyles C, Smith DK. Adherence to antiretroviral medications for HIV pre-exposure prophylaxis: lessons learned from trials and treatment studies. Am J Prev Med 2013;44:S91-8.

13 Kaul R, Prodger J, Joag V, et al. Inflammation and HIV transmission in subSaharan Africa. Curr HIVIAIDS Rep 2015;12:216-22.

14 Masson L, Passmore J-AS, Liebenberg LJ, et al. Genital inflammation and the risk of HIV acquisition in women. Clin Infect Dis 2015;61:260-9.

15 Passmore J-AS, Jaspan HB, Masson L. Genital inflammation, immune activation and risk of sexual HIV acquisition. Curr Opin HIV AIDS 2016;11:156-62.

16 Selhorst $P$, Masson L, Ismail SD, et al. Cervicovaginal inflammation facilitates acquisition of less infectious HIV variants. Clin Infect Dis. 2017;64:79-82.

17 Atashili J, Poole C, Ndumbe PM, et al. Bacterial vaginosis and HIV acquisition: a meta-analysis of published studies. AIDS 2008;22:1493-501.

18 McKinnon LR, Izulla P, Nagelkerke N, et al. Risk factors for HIV acquisition in a prospective Nairobi-Based female sex worker cohort. AIDS Behav 2015;19:2204-13.

19 McKinnon LR, Karim QA. Factors driving the HIV epidemic in southern Africa. Curr HIVIAIDS Rep 2016;13:158-69.

20 Klatt NR, Cheu R, Birse K, et al. Vaginal bacteria modify HIV tenofovi microbicide efficacy in African women. Science 2017;356:938-45.

21 Alfano M, Poli G. Role of cytokines and chemokines in the regulation of innate immunity and HIV infection. Mol Immunol 2005;42:161-82.

22 Bandzar S, Gupta S, Platt MO. Crohn's disease: A review of treatment options and current research. Cell Immunol 2013;286:45-52.

23 Janeway CA. Approaching the asymptote? evolution and revolution in immunology. Cold Spring Harb Symp Quant Biol 1989;54:1-13.

24 Medzhitov R, Janeway CA. Decoding the patterns of self and nonself by the innate immune system. Science 2002;296:298-300.

25 Akira S, Uematsu S, Takeuchi 0. Pathogen recognition and innate immunity. Cell 2006;124:783-801.

26 Blasius AL, Beutler B. Intracellular Toll-like receptors. Immunity 2010;32:305-15.

27 Kumar H, Kawai T, Akira S. Pathogen recognition by the innate immune system. Int Rev Immunol 2011;30:16-34.

28 Frasnelli ME, Tarussio D, Chobaz-Péclat V, et al. Tlr2 modulates inflammation in zymosan-induced arthritis in mice. Arthritis Res Ther 2005;7:R370-9.

29 Gambhir V, Yildiz C, Mulder R, et al. The TLR2 agonists lipoteichoic acid and Pam3CSK4 induce greater pro-inflammatory responses than inactivated Mycobacterium butyricum. Cell Immunol 2012;280:101-7.

30 Mukherjee S, Karmakar S, Babu SPS. TIr2 and TLR4 mediated host immune responses in major infectious diseases: a review. The Brazilian Journal of Infectious Diseases 2016;20:193-204.

31 Fang $\mathrm{H}$, Pengal RA, Cao X, et al. Lipopolysaccharide-Induced macrophage inflammatory response is regulated by SHIP. J Immunol 2004;173:360-6.

32 Porter KJ, Gonipeta B, Parvataneni S, et al. Regulation of lipopolysaccharideinduced inflammatory response and endotoxemia by $\beta$-arrestins. J Cell Physiol 2010;225:406-16.

33 Ngkelo A, Meja K, Yeadon M, et al. Lps induced inflammatory responses in human peripheral blood mononuclear cells is mediated through Nox4 and Gi-alpha dependent PI-3kinase signalling. J Inflamm 2012;9:1.

34 Płóciennikowska A, Hromada-Judycka A, Borzęcka K, et al. Co-Operation of TLR4 and raft proteins in LPS-induced pro-inflammatory signaling. Cell $\mathrm{Mol}$ Life Sci 2015:72:557-81. 
35 Xagorari A, Chlichlia K. Toll-Like receptors and viruses: induction of innate antiviral immune responses. Open Microbiol J 2008;2:49-59.

36 Jounai N, Kobiyama K, Takeshita F, et al. Recognition of damage-associated molecular patterns related to nucleic acids during inflammation and vaccination. Front Cell Infect Microbiol 2012;2:168.

37 Bernard MA, Han X, Inderbitzin S, et al. Hiv-Derived ssRNA binds to TLR8 to induce inflammation-driven macrophage foam cell formation. PLoS One 2014;9:e104039.

38 Levinson P, Kaul R, Kimani J, et al. Levels of innate immune factors in genital fluids: association of alpha defensins and LL-37 with genital infections and increased HIV acquisition. AIDS 2009;23:309-17.

39 Naranbhai V, Abdool Karim SS, Altfeld M, et al. Innate immune activation enhances HIV acquisition in women, diminishing the effectiveness of tenofovir microbicide gel. J Infect Dis 2012;206:993-1001.

40 Kahle EM, Bolton M, Hughes JP, et al. Plasma cytokine levels and risk of HIV type 1 (HIV-1) transmission and acquisition: a nested case-control study among HIV-1-Serodiscordant couples. J Infect Dis 2015;211:1451-60.

41 Iwasaki A, Medzhitov R. Control of adaptive immunity by the innate immune system. Nat Immunol 2015;16:343-53.

42 Koning FA, Otto SA, Hazenberg MD, et al. Low-Level CD4 ${ }^{+}$T Cell Activation Is Associated with Low Susceptibility to HIV-1 Infection. J Immunol 2005; 175:6117-22.

43 Joag VR, McKinnon LR, Liu J, et al. Identification of preferential CD4+ T-cell targets for HIV infection in the cervix. Mucosal Immunol 2016;9:1-12.

44 Zhang Zet al. Sexual transmission and propagation of SIV and HIV in resting and activated CD4+ T cells. Science 1999;286:1353-7.

45 Li Q, Estes JD, Schlievert PM, et al. Glycerol monolaurate prevents mucosal SIV transmission. Nature 2009;458:1034-8.

46 Paiardini M, Cervasi B, Reyes-Aviles E, et al. Low levels of SIV infection in sooty mangabey central memory CD4+ T cells are associated with limited CCR5 expression. Nat Med 2011;17:830-6.

47 Liebenberg LJP, Masson L, Arnold KB, et al. Genital-Systemic chemokine gradients and the risk of HIV acquisition in women. J Acquir Immune Defic Syndr 2017;74:318-25.

48 Kaul R, Rebbapragada A, Hirbod T, et al. Genital levels of soluble immune factors with anti-HIV activity may correlate with increased HIV susceptibility. AIDS 2008;22:2049-51.

49 Nkwanyana NN, Gumbi PP, Roberts L, et al. Impact of human immunodeficiency virus 1 infection and inflammation on the composition and yield of cervical mononuclear cells in the female genital tract. Immunology 2009;128:e746-57.

50 Arnold KB, Burgener A, Birse K, et al. Increased levels of inflammatory cytokines in the female reproductive tract are associated with altered expression of proteases, mucosal barrier proteins, and an influx of HIVsusceptible target cells. Mucosal Immunol 2016;9:194-205.

51 Gitter AH, Bendfeldt K, Schmitz H, et al. Epithelial barrier defects in HT-29/B6 colonic cell monolayers induced by tumor necrosis factor- $\alpha$. Ann N Y Acad Sci 2000;915:193-203.

52 Grotjohann I, Schmitz H, Fromm M, et al. Effect of TNF $\alpha$ and IFN $\gamma$ on epithelial barrier function in rat rectum in vitro. Ann NY Acad SCi 2000;915:282-6.

53 Mankertz J, Tavalali S, Schmitz H, et al. Expression from the human occludin promoter is affected by tumor necrosis factor alpha and interferon gamma. $J$ Cell Sci 2000;113:2085-90.

54 Nazli A, Chan O, Dobson-Belaire WN, et al. Exposure to HIV-1 directly impairs mucosal epithelial barrier integrity allowing microbial translocation. PLOS Pathog 2010;6:e1000852.

55 Ward H, Rönn M. Contribution of sexually transmitted infections to the sexual transmission of HIV. Curr Opin HIV AIDS 2010;5:305-10.

56 Mlisana K, Naicker N, Werner L, et al. Symptomatic vaginal discharge is a poor predictor of sexually transmitted infections and genital tract inflammation in high-risk women in South Africa. J Infect Dis 2012;206:6-14.

57 Masson L, Mlisana K, Little F, et al. Defining genital tract cytokine signatures of sexually transmitted infections and bacterial vaginosis in women at high risk of HIV infection: a cross-sectional study. Sex Transm Infect 2014;90:580-7.

58 Thurman AR, Kimble T, Herold B, et al. Bacterial vaginosis and subclinical markers of genital tract inflammation and mucosal immunity. AIDS Res Hum Retroviruses 2015:31:1139-52.

59 Anahtar MN, Byrne EH, Doherty KE, et al. Cervicovaginal bacteria are a major modulator of host inflammatory responses in the female genital tract. Immunity 2015;42:965-76

60 Masson L, Salkinder AL, Olivier AJ, et al. Relationship between female genital tract infections, mucosal interleukin-17 production and local T helper type 17 cells. Immunology 2015;146:557-67.
61 Alcendor DJ. Evaluation of health disparity in bacterial vaginosis and the implications for HIV-1 acquisition in African American women. American Journal of Reproductive Immunology 2016;76:99-107.

62 McLaren PJ, Ball TB, Wachihi C, et al. HIV-Exposed Seronegative Commercial Sex Workers Show a Quiescent Phenotype in the CD4 ${ }^{+} \mathrm{T}$ Cell Compartment and Reduced Expression of HIV-Dependent Host Factors. J Infect Dis 2010;202:S339-44.

63 Chege D, Chai Y, Huibner S, et al. Blunted IL17/IL22 and pro-inflammatory cytokine responses in the genital tract and blood of HIV-exposed, seronegative female sex workers in Kenya. PLoS One 2012;7:e43670.

64 Card CM, Keynan Y, Lajoie J, et al. Hiv controllers are distinguished by chemokine expression profile and HIV-specific T-cell proliferative potential. J Acquir Immune Defic Syndr 2012;59:427-37.

65 Lajoie J, Juno J, Burgener A, et al. A distinct cytokine and chemokine profile at the genital mucosa is associated with HIV-1 protection among HIV-exposed seronegative commercial sex workers. Mucosal Immunol 2012;5:277-87.

66 Prodger JL, Hirbod T, Kigozi G, et al. Immune correlates of HIV exposure without infection in foreskins of men from Rakai, Uganda. Mucosal Immunol 2014;7:634-44

67 Yao X-D, Omange RW, Henrick BM, et al. Acting locally: innate mucosal immunity in resistance to HIV-1 infection in Kenyan commercial sex workers. Mucosal Immunol 2014;7:268-79.

68 Lajoie J, Birse K, Mwangi L, et al. Using safe, affordable and accessible nonsteroidal anti-inflammatory drugs to reduce the number of HIV target cells in the blood and at the female genital tract. J Int AIDS Soc 2018;21:e25150.

69 Murray SM, Down CM, Boulware DR, et al. Reduction of immune activation with chloroquine therapy during chronic HIV infection. J Virol 2010;84:12082-6

70 Piconi S, Parisotto S, Rizzardini G, et al. Hydroxychloroquine drastically reduces immune activation in HIV-infected, antiretroviral therapy-treated immunologic nonresponders. Blood 2011;118:3263-72.

71 Paton NI, Goodall RL, Dunn DT, et al. Effects of hydroxychloroquine on immune activation and disease progression among HIV-infected patients not receiving antiretroviral therapy: a randomized controlled trial. JAMA 2012;308:353-61

72 Jacobson JM, Bosinger SE, Kang M, et al. The effect of chloroquine on immune activation and interferon signatures associated with HIV-1. AIDS Res Hum Retroviruses 2016;32:636-47.

73 Chen Y, Traore YL, Yang S, et al. Implant delivering hydroxychloroquine attenuates vaginal T lymphocyte activation and inflammation. J Control Release 2018:277:102-13.

74 Mori H, Arita K, Yamaguchi T, et al. Effects of topical application of betamethasone on imiquimod-induced psoriasis-like skin inflammation in mice. Kobe J Med Sci 2016;62:E79-88.

75 Milani M, lacobelli P. Vaginal use of ibuprofen isobutanolammonium (ginenorm): efficacy, tolerability, and pharmacokinetic data: a review of available data. ISRN Obstet Gynecol 2012;2012:6

76 Haase AT, Rakasz E, Schultz-Darken N, et al. Glycerol monolaurate microbicide protection against repeat high-dose SIV vaginal challenge. PLoS One 2015; 10:e0129465

77 Cromarty R, Sigal A, Liebenberg LJP, et al. Diminished HIV Infection of Target CD4+ T Cells in a Toll-Like Receptor 4 Stimulated in vitro Model. Front Immunol 2019:10:1705.

78 Freed EO, Englund G, Martin MA. Role of the basic domain of human immunodeficiency virus type 1 matrix in macrophage infection. J Virol 1995:69:3949-54.

79 Jaspan HB, Liebenberg L, Hanekom W, et al. Immune activation in the female genital tract during HIV infection predicts mucosal CD4 depletion and HIV shedding. J Infect Dis 2011;204:1550-6.

80 Hua S, Lécuroux C, Sáez-Cirión A, et al. Potential role for HIV-specific CD38-/ HLA-DR+ CD8+ T cells in viral suppression and cytotoxicity in HIV controllers. PLoS One 2014;9:e101920.

81 Gonzalez SM, Taborda NA, Correa LA, et al. Particular activation phenotype of T cells expressing HLA-DR but not CD38 in GALT from HIV-controllers is associated with immune regulation and delayed progression to AIDS. Immunol Res 2016;64:765-74.

82 Perfetto SP, Chattopadhyay PK, Lamoreaux L, et al. Amine-Reactive dyes for dead cell discrimination in fixed samples. Curr Protoc Cytom 2010; Chapter 9:9.34.1-9.34.14.

83 Hunka J, Riley JT, Debes GF. Approaches to overcome flow cytometry limitations in the analysis of cells from veterinary relevant species. BMC Vet Res 2020;16:83.

84 Hunter LJ, Wood DM, Dargan PI. The patterns of toxicity and management of acute nonsteroidal anti-inflammatory drug (NSAID) overdose. Open Access Emerg Med 2011:3:39-48. 
85 Stevenson M, Stanwick TL, Dempsey MP, et al. Hiv-1 replication is controlled at the level of $\mathrm{T}$ cell activation and proviral integration. Embo J 1990;9:1551-60.

86 Meditz AL, Haas MK, Folkvord JM, et al. Hla-Dr+ CD38+ CD4+ T lymphocytes have elevated CCR5 expression and produce the majority of R5-tropic HIV-1 RNA in vivo. J Virol 2011;85:10189-200.

87 Pan X, Baldauf H-M, Keppler OT, et al. Restrictions to HIV-1 replication in resting CD4+ T lymphocytes. Cell Res 2013;23:876-85.

88 Cao AT, Yao S, Gong B, et al. Th17 cells upregulate polymeric Ig receptor and intestinal IgA and contribute to intestinal homeostasis. J Immunol 2012;189:4666-73.

89 Reynolds JM, Martinez GJ, Nallaparaju KC, et al. Cutting edge: regulation of intestinal inflammation and barrier function by IL-17C. J Immunol 2012;189:4226-30.

$90 \mathrm{Xu} \mathrm{H}$, Wang X, Veazey RS. Th17 cells coordinate with Th22 cells in maintaining homeostasis of intestinal tissues and both are depleted in SIV-Infected macaques. J AIDS Clin Res 2014;05.

91 Card CM, Ball T, Fowke KR. Immune quiescence: a model of protection against HIV infection. Retrovirology 2013;10:141.

92 Card CM, Rutherford WJ, Ramdahin S, et al. Reduced cellular susceptibility to in vitro HIV infection is associated with CD4+ T cell quiescence. PLoS One 2012;7:e45911.

93 Licastro F, Davis LJ, Morini MC. Lectins and superantigens: membrane interactions of these compounds with $\mathrm{T}$ lymphocytes affect immune responses. Int J Biochem 1993;25:845-52.

94 Goldyne ME. Lymphocytes and arachidonic acid metabolism. Prog Allergy 1988;44:140-52.

95 Pablos JL, Santiago B, Carreira PE, et al. Cyclooxygenase- 1 and -2 are expressed by human T cells. Clin Exp Immunol 1999;115:86-90.

96 Paccani SR, Boncristiano M, Ulivieri C, et al. Nonsteroidal anti-inflammatory drugs suppress T-cell activation by inhibiting p38 MAPK induction. J Biol Chem 2002;277:1509-13.

97 Angst MS, Clark JD, Carvalho B, et al. Cytokine profile in human skin in response to experimental inflammation, noxious stimulation, and administration of a COX-inhibitor: a microdialysis study. Pain 2008;139:15-27.

98 Bessler H, Cohen-Terica D, Djaldetti M, et al. The effect of ibuprofen on cytokine production by mononuclear cells from schizophrenic patients. Folia Biol 2017;63:13-19.

$99 \mathrm{Hsia}$ J, Sarin N, Oliver JH, et al. Aspirin and thymosin increase interleukin-2 and interferon- $\gamma$ production by human peripheral blood lymphocytes. Immunopharmacology 1989;17:167-73.

100 Naarding MA, Baan E, Pollakis G, et al. Effect of chloroquine on reducing HIV-1 replication in vitro and the DC-SIGN mediated transfer of virus to CD4+ T-lymphocytes. Retrovirology 2007;4:6.

101 Furuichi K, Wada T, Sakai N, et al. Distinct expression of CCR1 and CCR5 in glomerular and interstitial lesions of human glomerular diseases. Am J Nephrol 2000;20:291-9.

102 Penton-Rol G, Cota M, Polentarutti N, et al. Up-Regulation of CCR2 chemokine receptor expression and increased susceptibility to the multitropic HIV strain 89.6 in monocytes exposed to glucocorticoid hormones. J Immuno 1999; 163:3524-9.

103 Mahla RS. Hiv-1 infection: the functional importance of SDF1, CCR2 and CCR5 in protection and therapeutics, 2015.

104 Michael NL, Louie LG, Rohrbaugh AL, et al. The role of CCR5 and CCR2 polymorphisms in HIV-1 transmission and disease progression. Nat Med 1997;3:1160-2.

105 Burton CT, Gotch FM, Imami N. CCR2/64I mutation detection in a HIV-1positive patient with slow CD4 T-cell decline and delay in disease progression. Int J STD AIDS 2005:16:392-5.

106 Malhotra R, Hu L, Song W, et al. Association of chemokine receptor gene (CCR2-CCR5) haplotypes with acquisition and control of HIV-1 infection in Zambians. Retrovirology 2011;8:22.

107 Ayroldi E, Cannarile L, Migliorati G, et al. Mechanisms of the antiinflammatory effects of glucocorticoids: genomic and nongenomic interference with MAPK signaling pathways. Faseb J 2012;26:4805-20.

108 Cain DW, Cidlowski JA. Immune regulation by glucocorticoids. Nat Rev Immunol 2017;17:233-47.

109 McKay LI, Cidlowski JA. Molecular control of immune/inflammatory responses: interactions between nuclear factor-kappa B and steroid receptor-signaling pathways. Endocr Rev 1999;20:435-59.
110 Coutinho AE, Chapman KE. The anti-inflammatory and immunosuppressive effects of glucocorticoids, recent developments and mechanistic insights. Mol Cell Endocrinol 2011;335:2-13.

111 Ai W, Li H, Song N, et al. Optimal method to stimulate cytokine production and its use in immunotoxicity assessment. Int J Environ Res Public Health 2013;10:3834-42.

112 Hantoushzadeh S, Javadian P, Salmanian B, et al. Betamethasone effects on the endocervical inflammatory cytokines in preterm labor: a randomized clinical trial. Int Immunopharmacol 2011;11:1116-9.

113 Ramesh G, Santana-Gould L, Inglis FM, et al. The Lyme disease spirochete Borrelia burgdorferi induces inflammation and apoptosis in cells from dorsal root ganglia. J Neuroinflammation 2013;10:88.

114 Ramesh G, Meisner OC, Philipp MT. Anti-Inflammatory effects of dexamethasone and meloxicam on Borrelia burgdorferi-induced inflammation in neuronal cultures of dorsal root ganglia and myelinating cells of the peripheral nervous system. J Neuroinflammation 2015;12:240.

115 Molins B, Mesquida M, Lee RWJ, et al. Regulatory T cell levels and cytokine production in active non-infectious uveitis: in-vitro effects of pharmacological treatment. Clin Exp Immunol 2015;179:529-38

116 Frank MG, Miguel ZD, Watkins LR, et al. Prior exposure to glucocorticoids sensitizes the neuroinflammatory and peripheral inflammatory responses to $E$. coli lipopolysaccharide. Brain Behav Immun 2010;24:19-30.

117 Rousseau GG. Control of gene expression by glucocorticoid hormones. Biochem J 1984;224:1-12.

118 Burnstein KL, Cidlowski JA. Regulation of gene expression by glucocorticoids. Annu Rev Physiol 1989;51:683-99.

119 Xavier AM, Anunciato AKO, Rosenstock TR, et al. Gene expression control by glucocorticoid receptors during innate immune responses. Front Endocrinol 2016;7:31.

120 Scheinman RI, Gualberto A, Jewell CM, et al. Characterization of mechanisms involved in transrepression of NF-kappa B by activated glucocorticoid receptors. Mol Cell Biol 1995; 15:943-53.

121 De Bosscher K, Schmitz ML, Vanden Berghe W, et al. GlucocorticoidMediated repression of nuclear factor-kappaB-dependent transcription involves direct interference with transactivation. Proc Natl Acad Sci U S A 1997;94:13504-9.

122 Kino T, Kopp JB, Chrousos GP. Glucocorticoids suppress human immunodeficiency virus type-1 long terminal repeat activity in a cell type-specific, glucocorticoid receptor-mediated fashion: direct protective effects at variance with clinical phenomenology. J Steroid Biochem Mol Biol 2000;75:283-90.

123 Kawasaki T, Kawai T. Toll-Like receptor signaling pathways. Front Immunol 2014;5:461.

124 McKinnon LR, Hughes SM, De Rosa SC, et al. Optimizing viable leukocyte sampling from the female genital tract for clinical trials: an international multi-site study. PLoS One 2014;9:e85675.

125 Gumbi PP, Nkwanyana NN, Bere A, et al. Impact of mucosal inflammation on cervical human immunodeficiency virus (HIV-1)-specific CD8 T-cell responses in the female genital tract during chronic HIV infection. J Virol 2008:82:8529-36.

126 Gosmann C, Anahtar MN, Handley SA, et al. Lactobacillus-Deficient cervicovaginal bacterial communities are associated with increased HIV acquisition in young South African women. Immunity 2017;46:29-37.

127 Souwer $\mathrm{IH}$, Bor JH, Smits P, et al. Assessing the effectiveness of topical betamethasone to treat chronic chilblains: a randomised clinical trial in primary care. Br J Gen Pract 2017;67:e187-93.

128 Kubin ME, Kokkonen N, Palatsi R, et al. Clinical Efficiency of Topical Calcipotriol/Betamethasone Treatment in Psoriasis Relies on Suppression of the Inflammatory TNF $\alpha$ - IL-23 - IL-17 Axis. Acta Derm Venereol 2017;97:449-55

129 Fine M. Quantifying the impact of NSAID-associated adverse events. Am J Manag Care 2013;19:s267-72.

130 Oray M, Abu Samra K, Ebrahimiadib N, et al. Long-Term side effects of glucocorticoids. Expert Opin Drug Saf 2016;15:457-65.

131 Widrig R, Suter A, Saller R, et al. Choosing between NSAID and Arnica for topical treatment of hand osteoarthritis in a randomised, double-blind study. Rheumatol Int 2007:27:585-91.

132 Dhar S, Seth J, Parikh D. Systemic side-effects of topical corticosteroids. Indian J Dermatol 2014:59:460-4. 